\title{
Pre-emptive National Monitoring Plan for Detecting the Amphibian Chytrid Fungus in Madagascar
}

\author{
Ché Weldon, ${ }^{1}$ Angelica Crottini, ${ }^{2}$ An Bollen, ${ }^{3}$ Falitiana C. E. Rabemananjara, ${ }^{4}$ Jamie Copsey, ${ }^{5}$ \\ Gerardo Garcia, ${ }^{6}$ and Franco Andreone ${ }^{7}$ \\ ${ }^{1}$ Unit for Environmental Science and Management, North-West University, Private Bag X6001, Potchefstroom 2520, South Africa \\ ${ }^{2}$ CIBIO, Centro de Investigação em Biodiversidade e Recursos Genéticos, Campus Agrário de Vairão, Rua Padre Armando Quintas, 4485-661 Vairão, \\ Portugal \\ ${ }^{3}$ Madagascar Fauna Group, BP 442, Morafeno, 501 Toamasina, Madagascar \\ ${ }^{4}$ Department of Animal Biology, University of Antananarivo, BP 906, 101 Antananarivo, Madagascar \\ ${ }^{5}$ International Training Centre, Durrell Wildlife Conservation Trust, Les Augres Manor, La Profonde Rue, Trinity, Jersey JE3 5BP, UK \\ ${ }^{6}$ North of England Zoological Society, Chester Zoo, Upton-by-Chester CH2 1LH, UK \\ ${ }^{7}$ Museo Regionale di Scienze Naturali, Via G. Giolitti, 36, 10123 Turin, Italy
}

Keywords: Batrachochytrium, chytridiomycosis, conservation medicine, inventory andmonitoring, amphibian declines

\section{INTRODUCTION}

The surveillance and monitoring of disease outbreaks in wildlife populations are particularly relevant today given the scale and rapidity of animal translocation and the associated rise in the emergence and re-emergence of diseases (Jebara 2004). Conservation authorities generally accept that no country is capable of ensuring absolute security of its borders by imposing quarantine measures or import bans on animals and animal products. Thus, any country is vulnerable to the risk of disease introduction, but countries that conduct disease surveillance of their wild animal populations are more likely to detect and promptly respond to the presence of infectious diseases (Mörner et al. 2002).

Chytridiomycosis is an emerging infectious disease that has a near global distribution (www.bd-maps.net). The amphibian chytrid fungus, Batrachochytrium dendrobatidis $(B d)$ is responsible for this disease and has gained much of

Published online: September 21, 2013

Correspondence to: Ché Weldon, e-mail: che.weldon@nwu.ac.za its current distribution through the international pet trade (Garner et al. 2006; Weldon and Fisher 2011). When $B d$ is newly introduced into novel populations, it is capable of causing major population declines, extirpations, and even extinctions (Berger et al. 1998; Bosch et al. 2001; Lips et al. 2005). Research by Farrer et al. (2011) showed that the global occurrence of $B d$ is the result of multiple emergences of distinct lineages of which one hypervirulent lineage (the BdGPL strain) is associated with the panzootic among amphibians. This raises questions about diagnostic test specificity, i.e., should a less specific test be favored in view of detecting related lineages, but at the expense of detecting other chytrids and resulting in false positives. In spite of the significant role chytridiomycosis plays in amphibian conservation, the development of survey protocols at the national level has received little attention by infected and uninfected countries, and diagnostic primer sets do not account for lineage diversity. The only published national survey exists for Australia (Skerratt et al. 2008), which details a standard method for sampling prioritized wild frog populations for infection with $B d$. 
Extensive, non-systematic surveys of Madagascar conducted in the late 2000s yielded no evidence of $B d$ when using histopathology (Weldon et al. 2008), conventional PCR (Crottini et al. 2011), or qPCR (Vredenberg et al. 2012). However, an unconfirmed finding was recently reported for the remote Makay Massif (Rabemananjara et al. 2011). The Makay survey made no attempt to decipher the chain of transmission or the source of infection (if any), and thus from an epidemiological and a fungal population genomics perspective the possible occurrence of $B d$ in Makay remains unconfirmed and deserves further investigation. No confirmed records of chytridiomycosis are encouraging, especially because Madagascar is branded one of the world's "amphibian arks" with 288 currently described species and near complete endemicity (Vieites et al. 2009). Without systematic monitoring, the amphibians of Madagascar are at risk of rapidly acquiring chytridiomycosis through an epizootic event should its introduction go unnoticed.

Monitoring wild frog populations for $B d$ infection was formally recognized as a strategic action that could significantly contribute toward the conservation of Madagascar's amphibians (Andreone et al. 2012). This leads to the establishment of the Chytridiomycosis Working Group (CWG), whose purpose it is to coordinate anti- $B d$ activities across Madagascar. Here, we present a pre-emptive $\mathrm{Na}$ tional Monitoring Plan (NMP) for $B d$ in Madagascar. The purpose of the NMP is primarily to detect $B d$ if and when it arrives in Madagascar at prioritized sites and to henceforth monitor chytridiomycosis trends.

\section{Survey Protocol}

The survey protocol of the NMP was designed to maximize the likelihood of detecting $B d$ while considering the availability of human and economic resources. The attribute for assessing chytridiomycosis, namely presence/absence of the pathogen can be obtained through the collection of amphibian skin swabs from a given population. Therefore, we based the methods of the protocol on principles that govern the biology of the host and pathogen. We used these criteria to design a repeatable and quantifiable sampling protocol.

\section{Frequency of Surveys}

Two surveys will be conducted every year. The first will be carried out during summer (November-February), which is warm and rainy for central and eastern Madagascar, but slightly drier in the west. This period coincides with the breeding season and major activity of most of the frog species. Overlapping the sampling period with the breeding season should increase the chances of detecting target species. A second survey will be conducted during the drycold period (May-July) and will enable us to sample juveniles that emerged from metamorphosis. Biannual surveys will ensure early detection of chytridiomycosis, since the intrinsic rate of change in infection status of a naïve population can occur rapidly after pathogen introduction.

\section{Survey Sites}

We evaluated sites for inclusion into the monitoring plan in the light of six criteria (Table 1). Anuran richness-high diversity and abundance implies high availability of hosts for $B d$ and potentially high disease transmission rates within anuran assemblages. Geographic distributionselecting biodiversity hotspots that are spatially distributed across the country in various bioregions and with varying elevation allow disease detection in a range of habitats. Baseline data-knowing the disease history (infected vs. non-infected) of a region helps to interpret current epidemiology patterns, thus sites where similar surveys had formerly been conducted benefit the monitoring objectives. $B d$-risk-a risk assessment using bioclimatic data from Madagascar that intercalates with the optimum physiological range of $B d$ based on the global $B d$ database distinguished regions where the pathogen is most likely to occur from regions where $B d$ is likely not to occur (Lötters et al. 2008). Proximity to air/seaports —act as points of entry that connect the island to disease pathways through trade and travel routes. Human resources-regions with organizations already involved in amphibian research should be preferred, since the existing manpower and skills can be applied to perform amphibian disease surveys.

We selected the following eight sites as long-term monitoring sites for $B d$ surveillance: Andasibe, Andohahela, Ankarafantsika, Ankaratra, Antoetra, Farankaraina, Ivoloina, and Menabe (Figure 1). The recent alarm provoked by the unconfirmed finding of $B d$ from the Makay Massif provides sufficient reason to survey this area at least once to confirm its $B d$ status. Data on species richness was provided as a qualitative indication based upon data obtained through consultation of the field guide by Glaw and Vences (2007). Baseline data was obtained from former $B d$ 
Table 1. Variability in selection criteria for each site included in the $B d$-monitoring plan

\begin{tabular}{llllllll}
\hline Site & $\begin{array}{l}\text { Geographic } \\
\text { position }\end{array}$ & $\begin{array}{l}\text { Elevation } \\
\text { range }\end{array}$ & $\begin{array}{l}\text { Anuran } \\
\text { richness }\end{array}$ & $\begin{array}{l}\text { Baseline } \\
\text { data }\end{array}$ & Bd-risk & $\begin{array}{l}\text { Near air/ } \\
\text { seaport }\end{array}$ & Responsible organization \\
\hline $\begin{array}{l}\text { Andasibe } \\
\text { Andohahela }^{\mathrm{a}}\end{array}$ & East & Mid & +++ & Yes & High & Yes & Mitsinjo Fikambanana \\
Ankarafantsika $^{\text {a }}$ & West & Mid & ++ & Yes & Low & Yes & Durrell Wildlife Conservation Trust \\
Ankaratra & Center & High & ++ & Yes & High & No & Langaha/UADBA \\
Antoetra & Center & High & ++ & No & High & No & Conservation International/UADBA \\
Farankaraina & North East & Low & ++ & Yes & High & No & Antongil Conservation \\
Ivoloina & East & Low & ++ & Yes & Medium & Yes & Madagascar Fauna Group \\
Menabe $^{\mathrm{a}}$ & West & Mid & + & No & Low & Yes & Durrell Wildlife Conservation Trust \\
\hline
\end{tabular}

${ }^{\text {a }}$ Protected areas.

Langaha Association Langaha, Riotinto/QMM Riotinto Quit Minerals Madagascar, UADBA University of Antananarivo, Department of Animal Biology.

surveys (Weldon et al. 2008; Rabemananjara et al. 2011). The selection of sites was influenced significantly by the predicted distribution of $B d$ that overlaps with areas of highest amphibian species richness (Andreone et al. 2005) and those identified as in situ conservation priorities for amphibians (Kremen et al. 2008).

\section{Sample Size}

It is important to sample a statistically significant number of specimens to avoid false negatives. The minimum sample size for each site should provide $95 \%$ confidence that infected specimens will be included in the sample, assuming a certain minimum prevalence of infection. In South Africa, $B d$ infection prevalence varies between 10 and $79 \%$ between populations and species (Weldon and Du Preez 2006; C.W., unpublished data). We therefore suggest that the species average expected pathogen prevalence for $B d$ in Madagascar should be $\geq 5 \%$. Assuming a prevalence of $5 \%$, a minimum of 50 animals per site have to be sampled in order to yield a statistically reliable result with $95 \%$ confidence (Digiacomo and Koepsell 1986). Admittedly, susceptibility varies among species resulting in different probabilities of detection, which in turn confounds the power of the detection statistic. However, if we assume that $B d$ spreads non-randomly throughout a region and we sample systematically throughout the site distribution of the target species, then our method of prediction is reliable at $95 \%$ certainty.

\section{Species Selection}

A minimum of one and a maximum of three indicator species will be monitored at each site. When fewer than 50 animals of a species can be found, the deficit will be made up with a second species, and if necessary a third species. Four species of Mantidactylus were selected as the priority species for all of the sites (M. betsileanus for Andohahela, Andasibe, Farankaraina, and Ivoloina; M. ulcerosus for Ankarafantsika; M. curtus for Ankaratra and M. lugubris for Antoetra), except Menabe for which Mantella betsileo was selected. The genus Mantidactylus is generally abundant where they occur and function as a common feature between the majority of monitoring sites, which is useful for performing comparative data analysis. Ptychadena mascareniensis was selected as the second species, because it has one of the widest distributions of all frogs in Madagascar. An exception was Antoetra for which Mantella cowanii was chosen. Mantella species are relevant due to their threatened conservation status and involvement in the pet trade, which renders them potential vectors for spreading disease across borders and makes them vulnerable to population declines. Owing to high population densities, five species of Heterixalus were selected as third species (H. punctatus, Andasibe; H. boettgeri, Andohahela; H. luteostriatus, Ankarafantsika and Menabe; H. betsileo, Ankaratra and Antoetra; H. madagascariensis, Farankaraina and Ivoloina). Every site has at least one species (M. betsilianus, $H$. betsileo, P. mascareniensis) shown to be susceptible to infection through ex-situ pathogen challenge (C.W., unpublished data), thus increasing the likelihood of detecting $B d$ if it occurs.

\section{Sample Collection}

A rigorous pathogen hygiene protocol will be employed during sampling to minimize accidental anthropogenic spread of $B d$ between sites and specimens (DAPTF 1998). 
On-site hygiene entails the disinfection of footwear and field equipment with a benzalkonium chloride solution at the commencement of fieldwork at each site. To prevent potential transmission of the fungus during frog handling disposable gloves should be worn and a "one bag - one frog" approach should be used. Nocturnal surveys will be most appropriate for collecting the species except for diurnal Mantella spp. Collection will be conducted by ground truthing suitable habitat such as forest leaf litter, beneath fallen logs, and the edges of ponds and streams, and catching by hand. In order to detect $B d$ on the collected specimens a skin swab sample must be taken. A sterile finetip swab is streaked five times over the ventral surface of the hind legs, feet, and drink patch. The swab is then broken off into a $1.5 \mathrm{ml}$ tube filled with $96 \% \mathrm{EtOH}$.

\section{Analysis of Swab Samples}

An agarose-based PCR assay will be used to analyze the swab samples for the presence of $B d$-DNA (Annis et al. 2004), and Proteinase $\mathrm{K}$ digestion $(10 \mathrm{mg} / \mathrm{ml}$ concentration) followed by a standard salt extraction protocol (Bruford et al. 1992) will be used to extract total genomic DNA. Presence of the pathogen will be detected using $B d$ specific primers: Bdla ( $5^{\prime}$-CAGTGTGCCATATGTCACG-3') and $\mathrm{Bd} 2 \mathrm{a}$ (5'-CATGGTTCATATCTGTCCAG-3') (Annis

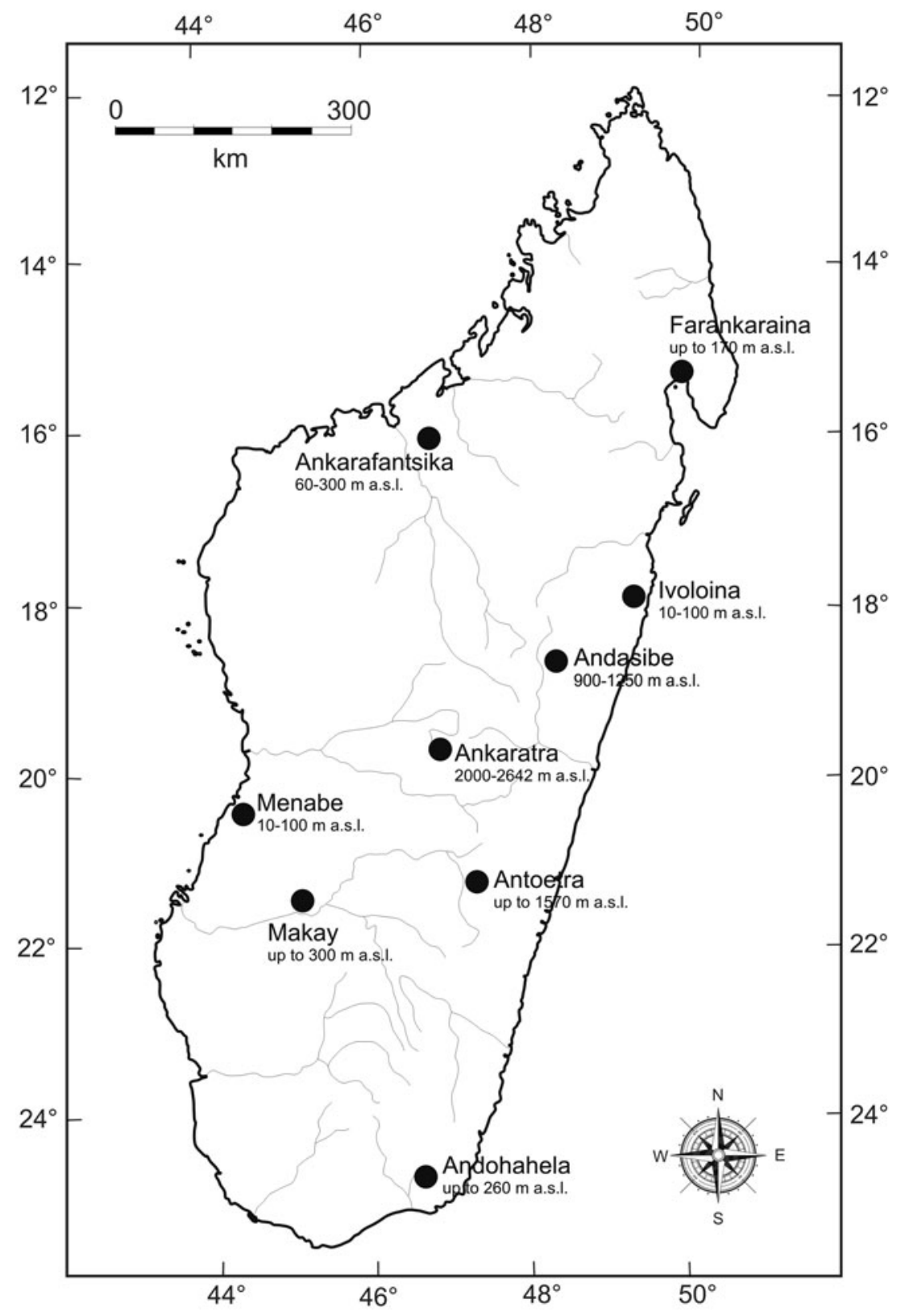

Figure 1. Distribution of survey sites for Madagascar's national $B d$-monitoring plan, including the locality of Makay. 
et al. 2004), designed from the ITS1 and ITS2 regions, respectively. PCRs will be performed following Federici et al. (2008), with the only exception of adding bovine serum albumin (BSA) to PCRs to reduce amplification inhibition for all DNA extracts (Garland et al. 2010). PCR products will be loaded onto $2 \%$ agarose gels, stained with ethidium bromide, and observed under ultraviolet light (365 nm). Samples will be scored as positive or negative for $B d$ occurrence based on the presence or absence of the approximately 300 bp band. Known $B d$-DNA will be used as positive control in all PCR runs (Federici et al. 2008). We acknowledge that a more sensitive diagnostic assay, realtime quantitative PCR (Boyle et al. 2004) is available that can detect $B d$ when its concentration is below the minimum threshold for agarose-based PCR (0.01 zoospore equivalents as opposed to 0.1 zoospore equivalents) and that agarose-based PCR has not been evaluated on all known $B d$ lineages. However, if $B d$ is present in Madagascar, and provided that the lineage is similar to globally distributed BdGPL commonly associated with amphibian population declines, then the likelihood of false negatives is minimal given our robust sampling protocol. In addition, molecular screening will be complimented with attempted recovery of $B d$ isolates (Longcore 2001) known for its application in fungal diagnostics. Once isolated, the chytrid cultures can then be sequenced to identify the relevant strain(s) (Farrer et al. 2011).

\section{DIsCUSSION}

The launch of the $B d$ NMP for Madagascar represents an important step in the conservation effort of the island's batrachofauna. Our NMP follows the unique approach of pre-emptive rather than reactionary surveillance of wildlife disease. The implementation of novel survey methods is warranted, because $B d$ distribution maps that often direct survey efforts are not available for Madagascar. Monitoring sites were strategically selected based amongst other on anuran richness and the likelihood of $B d$ occurring in the region, while three indicator species were chosen for each site. The use of indicator species has the advantage of not having to monitor all sympatric species, thus stretching human and monetary resources.

The recent discovery of three deeply diverged lineages of $B d$ (Farrer et al. 2011) has important implications for the diagnosis of $B d$ when an area is being surveyed for the first time or in Madagascar's case when existing diagnostic tests fail to detect $B d$. In such cases, a negative result could reflect the true absence of the pathogen or it could be a false negative when the existing diagnostic test fails to amplify a novel (e.g., Madagascar endemic) lineage. This appears to be the case in southeast Asia where Goka et al. (2009) recognized an endemic $B d$ lineage that was not detected by conventional $\mathrm{qPCR}$. If a similar lineage of $B d$ to that emerging in the rest of the world is present in Madagascar, then the chances of misclassifying a population are reduced. But when $B d$ is present in low prevalence, false negatives can easily result in the misclassification of a single population. Across many populations, however (such as in our NMP), it is unlikely that false negatives will occur in every case, reducing the likelihood of misclassification of an entire region (Smith and Weldon 2007). Ultimately diagnostic surveys in Madagascar have to be complimented with attempts at recovering $B d$ isolates from wild amphibian populations to determine strain identity and to optimize primers used for molecular diagnostics.

One of the major constraints for country-based projects in Madagascar is uncertainty about its longevity, thus its ability to transpire from a 3 -year project into a continuative program. The latter is an important component for a disease monitoring plan which requires long-term commitment from all major stakeholders in order for it to be sustainable. The synergy with other NGOs is vital, especially to cover logistical expenses and to train personnel who are ultimately responsible for generating the data upon which management decisions are to be based. Another auxiliary benefit is the development of local capacity in disease conservation that will enable the early detection of $B d$ in-country and which would allow rapid responses to imminent threat posed by a disease outbreak.

The implementation of our monitoring plan, together with the development of specific protocols aimed at mitigating chytridiomycosis in case it should arrive in Madagascar (Bletz et al. 2013), and the presence of an organization that coordinates $B d$-related research activities in Madagascar provide the strategic action required to rapidly respond to the challenges of a chytridiomycosis outbreak. Beside identifying the pathogen and controlling strategic sites, the collaboration between several organizations and scientific participants is an important way of developing and boosting the conservation science in Madagascar. Linking national disease surveillance of wild amphibian populations with international surveillance mechanisms will improve the global coverage and control of emerging infectious diseases of amphibians. 


\section{ACKNOWLEDGMENTS}

We thank the following participants of the Ivoloina workshop: T. Alexis, M. Badets, J. Catinaud, R. Dolch, D. Edmonds, K. Freeman, B. Iambana, I. Lau, J. Noel, N. Rabibisoa, L. Raharivololoniaina, H.F.J. Raholiarisendra, J.C. Rakotoarisoa, A. Rakotoarison, A.M.A. Rakotondrazafy, T. Rakotonjanahary, L. Rakotoson, C. Rambolamanana, L. Randriamanana, J. Randriamanarivo, T.M. Randriamoria, H. Randrianasolo, L. Randrianasolo, A.F. Ranjanaharisoa, T. Ratefason, J. Ratsimbazafy, H. Razafindraibe, E. Robsomanitrandrasana, G.F. Tahindrazana, and A. Toto Volahy. Research was supported by Gondwana Conservation and Research, Andy Sabin Family Foundation, Museo Regionale di Scienze Naturali, Amphibian Specialist Group, European Association of Zoos and Aquaria, MICET, Mohammed bin Zayed Species Conservation Fund, Wildcare Institute, and the National Research Foundation. A.C. was supported by a postdoctoral grant from the Portuguese "Fundação para a Ciência e Tecnologia" (FCT) (SFRH/BPD/72908/2010).

\section{REFERENCES}

Andreone F, Cadle JE, Cox N, Glaw F, Nussbaum RA, Raxworthy CJ, Stuart SN, Vallan D, Vences M (2005) Species review of amphibian extinction risk in Madagascar: conclusions from the Global Amphibian Assessment. Conservation Biology 19:17901802

Andreone F, Carpenter AI, Copsey J, Crottini A, Garcia G, Jenkins RKB, Köhler J, Rabibisoa NHC, Randriamahazo H, Raxworthy CJ (2012) Saving the diverse Malagasy amphibian fauna: where are we four years after implementation of the Sahonagasy Action Plan? Alytes 29:44-58

Annis SL, Dastoor FP, Ziel H, Daszak P, Longcore JE (2004) A DNA-based assay identifies Batrachochytrium dendrobatidis in amphibians. Journal of Wildlife Diseases 40:420-428

Berger L, Speare R, Daszak P, Green DE, Cunningham AA, Goggin CL, Slocombe R, Ragan MA, Hyatt AD, McDonald KR, Hines HB, Lips KR, Marantelli G, Parkes H (1998) Chytridiomycosis causes amphibian mortality associated with population declines in the rain forests of Australia and Central America. Proceedings of the National Academy of Sciences USA 95:9031-9036

Bletz MC, Loudon AH, Becker MH, Bell SC, Woodhams DC, Minbiole KPC, Harris RN (2013) Mitigating amphibian chytridiomycosis with bioaugmentation: characteristics of effective probiotics and strategies for their selection and use. Ecology Letters 16(6):807-820

Bosch J, Martinez-Solano I, Garcia-Paris M (2001) Evidence of a chytrid fungus infection involved in the decline of the common midwife toad (Alytes obstetricans) in protected areas of central Spain. Biological Conservation 97:331-337

Boyle DG, Boyle DB, Olsen V, Morgan JAT, Hyatt AD (2004) Rapid quantitative detection of chytridiomycosis (Batrachochytrium dendrobatidis) in amphibian samples using real-time Taqman PCR assay. Diseases of Aquatic Organisms 60:141-148

Bruford MW, Hanotte O, Brookfield JFY, Burke T (1992) Singlelocus and multilocus DNA fingerprint. In: Molecular genetic analysis of populations: a practical approach, Hoelzel AR (editor), Oxford: IRL Press, pp 225-270

Crottini A, Barbuto M, Casiraghi M, Andreone F (2011) A rapid amphibian survey at Itremo-Ambatofinandrahana, central Madagascar, with confirmed absence of chytrid fungus and recommendations for future monitoring activities. North-Western Journal of Zoology 7:346-351

DiGiacomo RF, Koepsell TD (1986) Sampling for detection of infection or disease in animal populations. Journal of the American Veterinary Medicine Association 189:22-23

Declining Amphibian Population Task Force (DAPTF) (1998) Fieldwork code of practice. http://www.fws.gov/ventura/species_ information/protocols_guidelines/docs/DAFTA.pdf. Accessed 6 November 2009

Federici S, Clemenzi S, Favelli M, et al. (2008) Identification of the pathogen Batrachochytrium dendrobatidis in amphibian populations of a plain area in the Northwest of Italy. Herpetology Notes 1:33-37

Farrer RA, Weinert LA, Bielby J, Garner TWJ, Balloux F, Clare F, Bosch J, Cunningham AA, Weldon C, du Preez LH, Anderson L, Kosakovsky-Pond SL, Shahar-Golan R, Henk D, Fisher MC (2011) Emergence of panzootic amphibian chytridiomycosis is unique to a single globalised hypervirulent lineage. PLoS Biology . doi:10.1073/pnas.1111915108

Garner TWJ, Perkins MW, Govindarajulu P, Seglie D, Walker S, Cunningham A, Fisher MC (2006) The emerging amphibian pathogen, Batrachochytrium dendrobatidis, globally infects introduced populations of the North American bullfrog, Rana catesbeiana. Biology Letters 2:455-459

Garland S, Baker A, Phillott AD, Skerratt LF (2010) BSA reduces inhibition in a TaqMan assay for the detection of Batrachochytrium dendrobatidis. Diseases of Aquatic Organisms 92:113116

Glaw F, Vences M (2007) Field guide to the amphibians and reptiles of Madagascar, 3rd ed., Cologne: Vences and Glaw Verlag

Goka K, Yokoyama J, Une Y, Kuroki T, Suzuki K, Nakahara M, Kobayashi A, Inaba S, Mizutani T, Hyatt AD (2009) Amphibian chytridiomycosis in Japan: distribution, haplotypes, and possible route of entry into Japan. Molecular Ecology 18:4757-4774

Jebara KB (2004) Surveillance, detection and response: managing emerging diseases at national and international levels. Scientific and Technical Review of the World Organisation for Animal Health 23:709-715

Kremen C, Cameron A, Moilanen A, Phillips SJ, Thomas CD, Beentje H, Dransfield J, Fisher BL, Glaw F, Good TC, Harper GJ, Hijmans RJ, Lees DC, Louis E Jr, Nussbaum RA, Raxworthy CJ, Razafimpahanana A, Schatz GE, Vences M, Vieites DR, Zjhra ML (2008) Aligning conservation priorities across taxa in Madagascar with high-resolution planning tools. Science 320:222-226

Lips KR, Burrowes PA, Mendelson JR III, Parra-Olea G (2005) Amphibian population declines in Latin America: a synthesis. Biotropica 37:222-226

Longcore JE (2001) Culture techniques for amphibian chytrids: recognizing, isolating, and culturing Batrachochytrium dendrobatidis from amphibians. In: Developing management strategies to control amphibian diseases: decreasing the risks due to communicable diseases, Speare R, Steering Committee of Getting the 
Jump on Amphibian Disease (editors), Townsville: School of Public Health and Tropical Medicine, James Cook University, pp 52-54

Lötters S, Rödder D, Bielby J, Bosch J, Garner TJW, Kielgast J, Schmidtlein S, Veith M, Walker S, Weldon C, Aanensen DA, Fisher MC (2008) Meeting the challenge of conserving Madagascar's megadiverse amphibians: addition of a risk-assessment for the chytrid fungus. PLoS Biology 6:ePub

Mörner T, Obendorf DL, Artois M, Woodford MH (2002) Surveillance and monitoring of wildlife diseases. Scientific and Technical Review of the World Organisation for Animal Health 21:67-76

Rabemananjara F, Andreone F, Rabibisoa N (2011) Madagascar and chytrid news: needed an urgent action and close collaboration between stakeholders. Froglog 97:33

Skerratt LF, Berger L, Hines HB, McDonald KR, Mendez D, Speare R (2008) Survey protocol for detecting chytridiomycosis in all Australian frog populations. Diseases of Aquatic Organisms 80:85-94

Smith K, Weldon C (2007) A conceptual framework for detecting oral chytridiomycosis in tadpoles. Copeia 4:1024-1028
Vieites DR, Wollenberg KC, Andreone F, Köhler J, Glaw F, Vences M (2009) Vast underestimation of Madagascar's biodiversity evidenced by an integrative amphibian inventory. Proceedings of the National Academy of Sciences USA 106:8367-8372

Vredenberg VT, du Preez Lh, Raharivololoniaina L, Vietes DR, Vences M, Weldon C (2012) A molecular survey across Madagascar does not yield positive records of the amphiban chytrid fungus Batrachochytrium dendrobatidis. Herpetology Notes 5:507-517

Weldon C, Du Preez LH (2006) Quantitative measurement of Batrachochytrium dendrobatidis in amphibian skin. Diseases of Aquatic Organisms 72:153-161

Weldon C, Du Preez LH, Vences M (2008) Lack of detection of the amphibian chytrid fungus (Batrachochytrium dendrobatidis) in Madagascar. Museo Regionale di Scienze Naturali di Torino 45:95-106

Weldon C, Fisher MC (2011) The effect of trade-mediated spread of amphibian chytrid on amphibian conservation. In: Fungal diseases: an emerging challenge to human, animal, and plant health, Institute of Medicine (IOM) (editor), Washington, DC: The National Academies Press, pp 355-367 